\title{
Genomic Aberrations and Cellular Heterogeneity in SV40-Immortalized Human Corneal Epithelial Cells
}

\author{
Kenta Yamasaki, ${ }^{1}$ Satoshi Kawasaki, ${ }^{1}$ Robert D. Young, ${ }^{2}$ Hideki Fukuoka, ${ }^{1}$ \\ Hidetoshi Tanioka, ${ }^{1}$ Mina Nakatsukasa, ${ }^{1}$ Andrew J. Quantock, ${ }^{2}$ and Shigeru Kinoshita ${ }^{1}$
}

\begin{abstract}
Purpose. Simian virus (SV) 40 -immortalized human corneal epithelial (HCE-T) cells have been widely used as an in vitro model of human corneal epithelial cells. The nature of this cell line was assessed for genomic aberrations and cellular heterogeneity.
\end{abstract}

Methods. For the quantitative measurement of genomic aberrations, array-based comparative genomic hybridization (CGH) analysis was performed. For identification of cellular heterogeneity, cell morphology, growth kinetics, transepithelial electrical resistance, and transfection/transcriptional efficiency were analyzed. Real-time PCR and chromosomal fluorescent in situ hybridization (cFISH) against some gained or lost loci were performed, to assess genomic heterogeneity. Expressed sequence tags (ESTs) for this cell line were collected to assess differences in the gene expression profiles between HCE-T cells and normal corneal epithelial cells. Southern blot analysis and inverse PCR analyses were used to determine the genomic integration site of the SV40 large T antigen gene (LTAG).

Results. Array CGH analysis demonstrated that the genomic content of HCE-T cells is different from the normal healthy genome. The results from cellular functional assays, real-time PCR, and cFISH strongly indicated that HCE-T cells consist of a significant number of heterogeneous cell populations. The genomic integration site of the SV40 large T antigen was at p22.1 of chromosome 9.

Conclusions. The results indicate that HCE-T cells have an altered genomic content and that they are composed of heterogeneous cell populations. This should be considered when conducting experiments or interpreting the results of studies that use this cell line. (Invest Ophthalmol Vis Sci. 2009;50: 604-613) DOI:10.1167/iovs.08-2239

Simian virus (SV)40-immortalized human corneal epithelial $\checkmark$ (HCE-T) cells were established in 1995 by Araki-Sasaki et al. ${ }^{1}$ to be used as an in vitro model for human corneal epithelial cells. Although several types of cell line currently exist for this

From the ${ }^{1}$ Department of Ophthalmology, Kyoto Prefectural University of Medicine, Kyoto, Japan; and the ${ }^{2}$ School of Optometry and Vision Sciences, Cardiff University, Cardiff, United Kingdom.

Supported by Grants-in-aid 19592033 and 20390451 from the Japanese Ministry of Education, Science, Culture and Sports, and a grant from the Japanese Ministry of Health, Labor, and Welfare. This work was also supported by a research fund from the Kyoto Foundation for the Promotion of Medical Science.

Submitted for publication May 3, 2008; revised July 14 and August 15, 2008; accepted November 19, 2008.

Disclosure: K. Yamasaki, None; S. Kawasaki, None; R.D. Young, None; H. Fukuoka, None; H. Tanioka, None; M. Nakatsukasa, None; A.J. Quantock, None; S. Kinoshita, None

The publication costs of this article were defrayed in part by page charge payment. This article must therefore be marked "advertisement" in accordance with 18 U.S.C. $\$ 1734$ solely to indicate this fact.

Corresponding author: Satoshi Kawasaki, Department of Ophthalmology, Kyoto Prefectural University of Medicine, 465 Kajii-cho, Hirokoji-agaru, Kawaramachi-dori, Kamigyo-ku, Kyoto 602-0841, Japan; bluenova@koto.kpu-m.ac.jp. specific epithelial cell type ${ }^{2-7}$ the HCE-T cell line appeared to be the one most favored and frequently used, possibly because it is free of infectious virus particles and is easy to maintain. The HCE-T cell line has historically been used for a range of studies, most of which are involved in drug development, ${ }^{8,9}$ elucidation of cellular signaling pathways, ${ }^{10,11}$ or molecular interactions maintaining homeostasis of normal corneal epithelial cells.

Immortalization of the HCE-T cells was performed by adenoviral introduction of the large $\mathrm{T}$ antigen gene (LTAG), originally encoded within the SV40 viral genome. ${ }^{12}$ Its translation product functions as a viral oncoprotein binding to $\mathrm{p} 53$ (TP53) and retinoblastoma ( $R B)-1$ proteins via respective binding domains, thereby inhibiting their functions in a variety of animal cells. ${ }^{13}$ Since both of these proteins have strong antitumor activity, ${ }^{14-16}$ cells expressing this oncoprotein have an inclination toward oncogenic transformation. This raises the possibility for the generation of rare cells that can survive crisis $^{15}$ and ultimately yields an infinite replicative lifespan.

Genomic aberrations, including various types of mutations or numerical/structural chromosomal aberrations, primarily occur during cell division or when cells are exposed to various types of mutagens. In normal somatic cells, the cell cycle of those possessing an aberrant genome is stopped or the cell is or removed via various types of cell cycle check-point mechanisms ${ }^{17}$ to avoid tumor evolution. Since TP53 and RB1 play a central role in such error-correcting mechanisms, ${ }^{18,19}$ cells lacking these genes may accumulate abnormal genomic contents with each cell division. In fact, most of the naturally occurring cancers and immortalized cell lines have been found to lose one or both of these proteins ${ }^{14,20}$ and to have disordered genomic contents, as measured by karyotypic analysis ${ }^{21}$ or, much more intimately, by classic or array-based comparative genomic hybridization (CGH) analysis. ${ }^{22}$ Therefore, after extensive passages, HCE-T cells may have an altered genomic content, as reported in other SV40-immortalized cell lines. ${ }^{23,24}$ In addition, HCE-T cells may be composed of numerous heterogenous cell populations, since such genomic aberrations may randomly occur and may be variable among individual cells. So, although HCE-T cells were reported to be derived from a single clone and were well-characterized from the biochemical points of view when they were initially established, that situation may not be the case now. This study was performed to gain better understanding of the current status of HCE-T cells in view of genomic aberrations and cellular heterogeneity.

\section{Materials ANd Methods}

\section{Cell Culture}

After the absence of mycoplasma contamination was confirmed, HCE-T cells (passage number: 62) were cultured in DMEM/F12 medium supplemented with $10 \% \mathrm{FBS}, 10 \mathrm{ng} / \mathrm{mL}$ EGF, $5 \mu \mathrm{g} / \mathrm{mL}$ insulin, $0.1 \mu \mathrm{g} / \mathrm{mL}$ cholera toxin, and penicillin/streptomycin in an incubator supplied with $95 \%$ air and $5 \% \mathrm{CO}_{2}$ at $37^{\circ} \mathrm{C}$, according to a previous report. ${ }^{25}$ 
TAble 1. Summarized List of All Primers Used in the Study

\begin{tabular}{ll}
\hline Primer Name & Sequence \\
\hline
\end{tabular}

\section{Real-time PCR}

$\begin{array}{ll}\text { Luc-F } & \text { GTACACCTTCGTGACTTCCCATTT } \\ \text { Luc-R } & \text { TTTTGTCCCGGTCGAAGCT } \\ \text { PPM1L-F } & \text { TCTATGGCTAAAAACAATAACCA } \\ \text { PPM1L-R } & \text { GAGGGCTGCAATCTGTTTTG } \\ \text { PCDH10-F } & \text { GTTGACATAAAAGTAAAAGGCAAGC } \\ \text { PCDH10-R } & \text { CATTATTGTTTCAGTATTCCATGTG } \\ \text { CSMD1-F } & \text { TCGGGGGCTAGAGATACACATGC } \\ \text { CSMD1-R } & \text { AGAGAACACAGCCGACAGAATAAC } \\ \text { AMOTL1-F } & \text { GTGGATATATTTGCTTACATTCCG } \\ \text { AMOTL1-R } & \text { TCTTGTATCAGCCCCCAAAG } \\ \text { FDX1-F } & \text { AGACCAAGCCCTTTTGCTAAG } \\ \text { FDX1-R } & \text { TTTCTTTCGTTTCGCCTC } \\ \text { MCF2-F } & \text { ACATGGACACAAGCTTGCAG } \\ \text { MCF2-R } & \text { ATGCATTTTGAAGGTCCTGC } \\ \text { CREB5-F } & \text { TCTACTTAGAGAATGATTCCCATCC } \\ \text { CREB5-R } & \text { CATGAAATACGCTTAGCCTGC }\end{array}$

\section{Southern Blot}

Probe1-F

Probe1-R

Probe2-F

Probe2-R

\section{Inverse PCR}

Mbo-1-F

Mbo-1-R

Mbo-2-F

Mbo-2-R

Mbo-3-F

Mbo-3-R

Pst-common-F

Pst-1-R

Pst-2-R

Pst-3-R

\section{ACATGTAAGCGACGGATGTG \\ CCCCCTGAACCTGAAACATA \\ GGCGGGTGACGTAGTAGTGT \\ GCGAAAATGGCCAAATCTTA}

\section{Array CGH}

Genomic DNA was extracted from $1 \times 10^{6}$ HCE-T cells (DNAeasy blood and tissue kit; Qiagen, Tokyo, Japan). Genomic DNA from a normal human female (Promega, Madison, WI) was used as a normal control. These DNAs were labeled respectively with $\mathrm{Cy} 5$ and $\mathrm{Cy} 3$ fluorophores, purified, mixed together, and hybridized against a $244-\mathrm{k}$ microarray for array CGH (Agilent Technologies, Palo Alto, CA), which spans the entire human genome at a median resolution of 7.4 or 16.5 $\mathrm{kb}$ for coding and noncoding regions, respectively. Hybridized fluorescence signals were captured and analyzed (CGH Analytics software; Agilent Technologies, Palo Alto, CA).

\section{Subcloning of the HCE-T Cells}

Subcloning of the HCE-T cells was performed by the limited-dilution method. In brief, trypsin-dissociated HCE-T cells were transferred to wells of a 96-multiwell plate at an average cell density of 0.5 cells per well. Only subclones, which were confirmed to be of a single colony, were subcultured for subsequent experiments.

\section{Scanning Electron Microscopy (SEM)}

Cells were cultured on coverslips (Thermanox; Agar Scientific, Stansted, UK). Five days after the cells reached confluence, they were fixed by immersion of the coverslips in $2.5 \%$ phosphate-buffered glutaraldehyde ( $\mathrm{pH} 7.4$ ) for 60 minutes, postfixed in $1 \%$ osmium tetroxide for 20 minutes, washed in distilled water, contrasted in $0.5 \%$ uranyl acetate, and dehydrated in ethanol. The cells were dried at room temperature after infiltration with hexamethyldisilazane (HMDS). The coverslips were mounted on aluminum stubs with carbon cement (Leit-C; Plano GmbH, Wetzlar, Germany), gold-coated in a sputtercoater (EMscope COOE; Emitech, Ashford, UK), and examined by scanning electron microscope (Philips XL20; FEI Co., Eindhoven, The Netherlands).

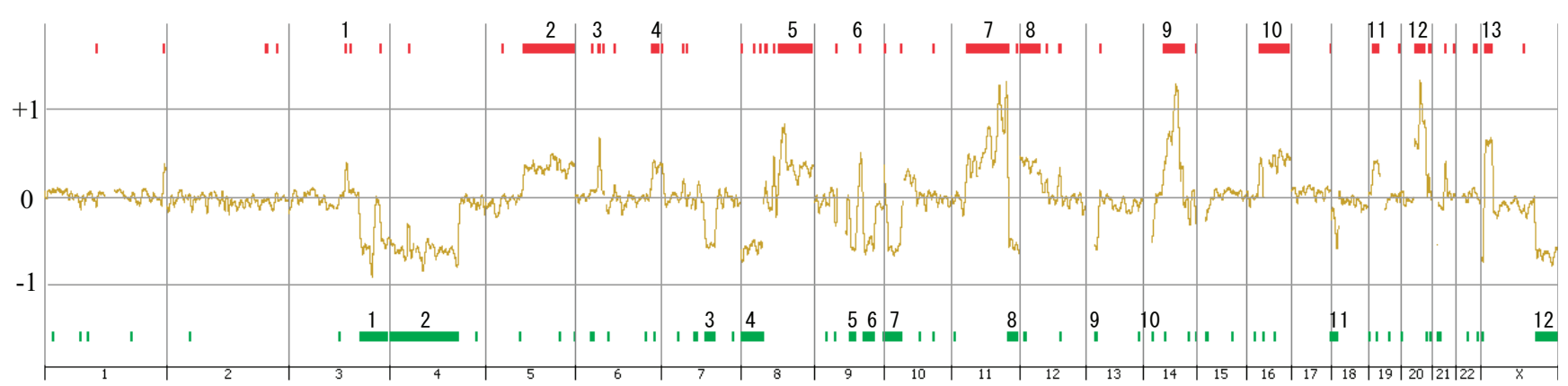

A
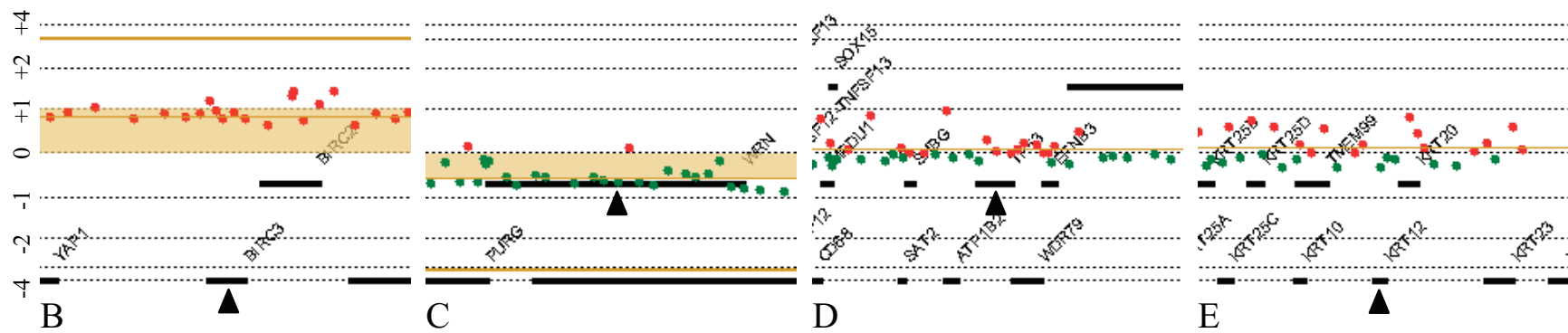

FigURE 1. Results of array CGH analysis. (A) The value of log-transformed relative hybridization signals for probes within $2 \mathrm{Mb}$ of the genomic region was averaged and scatterplotted against the whole human genome longitudinally from the short arm of chromosome 1 to the long arm of chromosome $\mathrm{X}$. Since the HCE-T cells were transformed from corneal epithelial cells derived from a female, no data for the Y chromosome are demonstrated. Regions that were determined to be aberrant by the ADM-2 algorithm are indicated in red (top) or green (bottom), indicating gain or loss, respectively. The array CGH data have been deposited in the NCBI Gene-Expression Omnibus (GEO, http://www.ncbi.nlm.nih.gov/projects/geo/ National Center for Biotechnology Information), and are freely accessible under accession number GSM278477. (B-E) Local CGH data for four selected gene loci. An oncogenic gene locus (BIRC3) was gained (B) and a tumor-suppressor gene locus (WRN) was lost (C). The TP53 (D) and KRT12 (E) gene loci remained unchanged. 


\section{Growth Kinetics Determined by Population-Doubling (PD) Analysis}

Each of the HCE-T subclones was seeded at $2 \times 10^{4}$ to $1 \times 10^{5}$ in a T25 plastic flask. The next day, cells that failed to reattach were collected and counted. The attached cells were fed every other day and harvested at 3 to 5 days, while their growth was still in a mid-log phase, a time at which cell confluence is roughly less than $70 \%$. Then, the harvested subclones were repeatedly passaged using the same procedure as described earlier. The increment of PD per passage was calculated with the formula $\log _{2}\left[C_{\mathrm{h}} /\left(C_{\mathrm{s}}-\mathrm{C}_{\mathrm{f}}\right)\right]$, where $C_{\mathrm{h}}$ corresponds to the number of harvested cells, $C_{\mathrm{s}}$ to the number of seeded cells, and $C_{\mathrm{f}}$ to the number of cells that failed to reattach.

\section{Transepithelial Electrical Resistance (TER)}

Subcloned HCE-T cells were seeded at $8 \times 10^{4}$ cells on a porous membrane (0.4- $\mu \mathrm{m}$ Transwell; Corning, Inc., Corning, NY) and were grown to form a confluent monolayer. TER was monitored daily for 21 days using an epithelial voltohmmeter (EVOM; World Precision Instruments, Inc., New Haven, CT). The measured TER was subtracted from the background TER, determined on a blank membrane, and further normalized by the area of the monolayer as transepithelial electrical resistivity (in ohms per square centimeter). The number of replicates for each subclone was five.

\section{Transfection and Transcription Efficiency}

A plasmid vector harboring a firefly luciferase gene (pGL4.13[luc2/ SV40] Vector; Promega) or a modified GFP gene (pmaxGFP; Amaxabiosystems, Cologne, Germany) was introduced into each of the subcloned HCE cells (Lipofectamine LTX; Invitrogen Corp., Carlsbad, CA). After a 24-hour incubation, the cells were lysed and respectively subjected to a luciferase assay (Dual-Luciferase Reporter Assay System; Promega) or fluorometric analysis (VersaFluo; Bio-Rad Laboratories, Inc., Hercules, CA), along with a chemiluminescence cell-titer assay (Celltiter-Glo; Promega). Data from both reporter assays were normalized with data from the cell-titer assay. The introduced luciferase vector DNA was also quantitated by real-time PCR to monitor its transfection efficiency. All experiments were performed in triplicate.

\section{Quantitation of Locus Copy Number by Real-Time PCR}

The copy number of some gained or lost genomic loci was quantitated by real-time PCR (Prism 7000 Sequence Detection System; Applied

Table 2. List of Highly Altered Loci in HCE-T Cells

\begin{tabular}{|c|c|c|c|c|}
\hline $\begin{array}{l}\text { No. of } \\
\text { Region* }\end{array}$ & $\begin{array}{l}\text { Cytogenic } \\
\text { Band }\end{array}$ & Oncogenes† & Tumor-Suppressor Genes $\ddagger$ & $\begin{array}{l}\text { Corneal Epithelial } \\
\text { Cell-Specific Genes } ₫\end{array}$ \\
\hline \multicolumn{5}{|l|}{ Gain } \\
\hline 1 & $3 q 13.2-q 13.31$ & & & \\
\hline 2 & $5 q 14.1-q 35.3$ & $\begin{array}{l}\text { ACSL6, AFF4, APC, } \\
\text { ARHGAP26, CSF1R, FLT4, } \\
\text { NPM1, NSD1, PDGFRA, TLX3 }\end{array}$ & APC, CTNNA1, MCC & $\begin{array}{l}\text { CXCL14, HSPA9, TGFB1, } \\
\text { TRIM36 }\end{array}$ \\
\hline 3 & $6 \mathrm{p} 12.3$ & & & \\
\hline 4 & $6 q 25.2-q 27$ & FGFR1OP, MAS1, MLLT4 & & \\
\hline 5 & $8 \mathrm{q} 21.11-\mathrm{q} 24.3$ & COX6C, MYC, RUNX1T1 & EXT1, RECQL4 & FABP5, RPL8 \\
\hline 6 & $9 \mathrm{q} 22.31-\mathrm{q} 22.32$ & & FANCC, PTCH & \\
\hline 7 & $11 \mathrm{p} 13-\mathrm{q} 23.1$ & $\begin{array}{l}\text { BIRC3, CCND1, DDX1O, FGF3, } \\
\text { FGF4, LMO2, MAML2, } \\
\text { NUMA1, PICALM, POU2AF1 }\end{array}$ & $\begin{array}{l}A T M, D D B 2, E X T 2, M E N 1, P P P 2 R 1 B \\
\quad S D H D, W T 1\end{array}$ & $\begin{array}{c}\text { AK026607, EIF3M, GSTP1, } \\
\text { FTH1, PRDX5, TIMM8B }\end{array}$ \\
\hline 8 & $12 \mathrm{p} 13.33-\mathrm{q} 12$ & ERC1, ETVG, KRAS, ZNF384 & & MLF2 \\
\hline 9 & $14 \mathrm{q} 21.1-\mathrm{q} 24.2$ & $G P H N, R A D 51 L 1$ & & \\
\hline 10 & $16 \mathrm{p} 12.1-\mathrm{q} 24.3$ & СВFА2T3, СВFВ, FUS & $C D H 1, C Y L D, F A N C A$ & $M T 1 X, N Q O 1$ \\
\hline 11 & 19p13.2-p12 & BRD4, CRTC1, ELL, LYL1, TPM4 & $C D K N 2 D$ & \\
\hline 12 & $20 \mathrm{q} 11.21-\mathrm{q} 13.2$ & GNAS, TOP1 & & LPIN3 \\
\hline 13 & $\mathrm{Xp} 22.31-\mathrm{p} 21.3$ & & & \\
\hline \multicolumn{5}{|l|}{ Loss } \\
\hline 1 & $3 q 23-q 29$ & $\begin{array}{l}\text { BCL6, EIF4A2, EVI1, GMPS, } \\
\text { LPP, MDS1, MLF1, TFRC }\end{array}$ & & \\
\hline 2 & $4 \mathrm{p} 16.3-\mathrm{q} 31.1$ & $\begin{array}{l}\text { AFF1, CHIC2, FGFR3, FIP1L1, } \\
\text { KIT, PDGFRA, RAP1GDS1, } \\
\text { RHOH, TEC }\end{array}$ & & \\
\hline 3 & 7q21.13-q31.1 & & & \\
\hline 4 & $8 \mathrm{p} 23.3-\mathrm{q} 11.21$ & MYST3, PCM1, WHSCIL1 & WRN & $C L U$ \\
\hline 5 & $9 \mathrm{q} 21.13-\mathrm{q} 21.33$ & & & \\
\hline 6 & $9 q 22.33-q 33.2$ & CEP1, TAL2 & $X P A$ & KIAA0368 \\
\hline 7 & 10p14-p11.21 & MLLT1O & & \\
\hline 8 & $11 \mathrm{q} 23.1-\mathrm{q} 25$ & $\begin{array}{l}\text { ARHGEF12, CBL, FLI1, MLL, } \\
\quad \text { ZBTB16 }\end{array}$ & & APLP2, TMPRSS4 \\
\hline 9 & $13 q 11-q 12.13$ & ZNF198 & & GJB2 \\
\hline 10 & 14q11.1-q11.2 & CCNB1IP1, GOLGA5,TRA@ & & \\
\hline 11 & 18p11.22-p11.21 & & & \\
\hline 12 & Xq23-q28 & MCF2, SEPT6 & GPC3 & \\
\hline
\end{tabular}

${ }^{*}$ Number of aberrant regions correspond to those in Figure 1.

$\dagger$ Listed oncogenes are cited in Futreal et al. ${ }^{27}$

‡ The listed tumor-suppressor genes were obtained from a publicly accessible Web book (Cancer Medicine, Table 7-1; http://www.ncbi.nlm. nih.gov/books/bv.fcgi?rid=cmed6.table.1598; National Center for Biotechnology Information, Bethesda, MD).

$\S$ Listed genes are specifically expressed in in vivo corneal epithelial cells. 
Biosystems [ABI] Japan, Ltd., Tokyo, Japan) using genomic DNA from the subcloned HCE-T cells in a fluorescence-containing PCR buffer (SYBR Green Master Mix; ABI Japan, Ltd.). Primer pairs were designed against the selected genomic loci (Table 1, and see Fig. 6) by referring to the Uni-STS database (http://www.ncbi.nlm.nih.gov/sites/entrez?db= unists/ provided in the public domain by the National Center for Biotechnology Information, Bethesda, MD). Before analysis, each primer pair was confirmed to produce a specific amplified product. All experiments were performed in duplicate.

\section{Chromosomal Fluorescent In Situ Hybridization (cFISH)}

The copy number of a genomic locus was further assessed by cFISH. In brief, each subclone was cultured and the cell cycle stopped at metaphase with $20 \mathrm{ng} / \mathrm{mL}$ of colcemide for 2 hours, swollen in a hypotonic buffer $(0.05 \mathrm{M} \mathrm{KCl})$, fixed with Carnoy's fixative, and dropped onto a silanated glass slide to make a metaphase spread. A BAC plasmid (RP11-506N24), covering a genomic region close to the FDX1 gene locus (11q22.3), was restriction-digested with Sau3AI, random-labeled with 16-biotin dUTP, and its repetitive sequences were masked with Cot-1 DNA. The metaphase spread of each of the HCE-T subclones was denatured, hybridized with the biotin-labeled probe, washed, incubated with streptavidin-HRP, developed with fluorescence-labeled (Alexa488) tyramide (Invitrogen Corp.), counterstained with DAPI, and photographed with a laser-confocal fluorescence microscope (TCS SP2 AOBS; Leica Microsystems, Co., Ltd., Wetzlar, Germany).

\section{Genomic Southern Blot Analysis}

The integration site of the SV40-LTAG in the genome of subcloned HCE-T cells was analyzed by genomic Southern blot analysis. In brief, a partial sequence of the left arm of the adenoviral vector (Probe 1, see Fig. 8A) was PCR-amplified, gel-purified, and ${ }^{32} \mathrm{P}$-labeled with a random labeling kit (Rediprime II DNA Labeling System; GE Healthcare UK Ltd., Buckinghamshire, UK). Genomic DNA, extracted from each of the subcloned HCE-T cells, was restriction-digested with PstI, electrophoresed on a $0.7 \%$ agarose gel, and transferred to a nylon membrane. The blotted nylon membrane was hybridized with the RI-labeled probe, washed, autoradiographed against a radio-sensitive imaging plate (BASMS2025; Fuji Film, Tokyo, Japan), and scanned with an image analyzer (BAS5000; Fuji Film).

\section{Inverse PCR}

The integration site of SV40-LTAG was further determined by inverse PCR. In brief, genomic DNA (HCE-T-15) was digested with PstI or MboI, self-ligated, and PCR-amplified with a pair of primers, both directing outward from the left arm of the adenoviral vector. The amplified products were electrophoresed, gel purified, and sequenced (BigDye 3.1; ABI Japan, Ltd.). The obtained sequence data was then scanned for the entire human genome (Blat software; http://genome. brc.mcw.edu/cgi-bin/ provided in the public domain byUCSC Genome Browser, University of California at Santa Cruz, Santa Cruz, CA).

\section{EST Analysis}

Ranked RNA expression in the HCE-T cells was analyzed as described elsewhere. ${ }^{26}$ In brief, double-stranded cDNA was synthesized with a pUC119-based vector primer, digested with $\mathrm{MboI}$ and Bam HI restriction enzymes to obtain the same $5^{\prime}$ overhang at both ends, self-ligated, and transformed into JM-109-competent Escherichia coli cells (Toyobo, Tokyo, Japan). After overnight incubation, the colonies were picked, isothermally amplified (Templiphi; GE Healthcare), and sequenced. The obtained sequence data was then trimmed, repeatmasked, and scanned against human transcript databases.

\section{Statistical Analysis}

Statistical analysis was performed on a computer with commercially available statistics software (SAS ver 9.1, SAS Institute Inc., Cary, NC).
For growth kinetics, TER, and gene transfer and transcription efficiency, one-factor analysis of variance (ANOVA), was performed to test whether the average values for these experiments were identical among subclones.

\section{Results}

\section{Genomic Aberration in HCE-T Cells}

Array CGH data indicated that the HCE-T cells manifested an aberrant genomic content compared with the normal human genome; some genomic regions were gained while others were lost (Fig. 1A). Significantly gained regions were found in chromosomes $3,5,6,8,9,11,12,14,16,19,20$, and $\mathrm{X}$, while significantly lost regions were found in chromosomes $3,4,7,8$, $9,10,11,13,14,18$, and $\mathrm{X}$ (Table 2). In some chromosomes, some regions were gained, whereas others remained unchanged or were lost. Thus, the genomic aberrations do not simply correspond to numerical chromosomal abnormalities (aneuploidy or polyploidy) but point to the existence of more complicated situations such as aneuploidy combined with chromosomal fusion, reciprocal or nonreciprocal translocation, locus amplification or deletion, or double minute chromosome. As listed in Table 2, some oncogenes were gained and some tumor-suppressor genes were lost, indicating that such alterations may individually or cooperatively contribute to the enhancement of the growth activity of HCE-T cells. Conversely, some tumor-suppressor genes were gained and some oncogenes were lost, implying that not all these alterations are related to the oncogenic transformation of this cell line. It is possible that most of the observed genomic aberrations reflect the accumulations of randomly occurring alterations without any impact on oncogenic transformation.
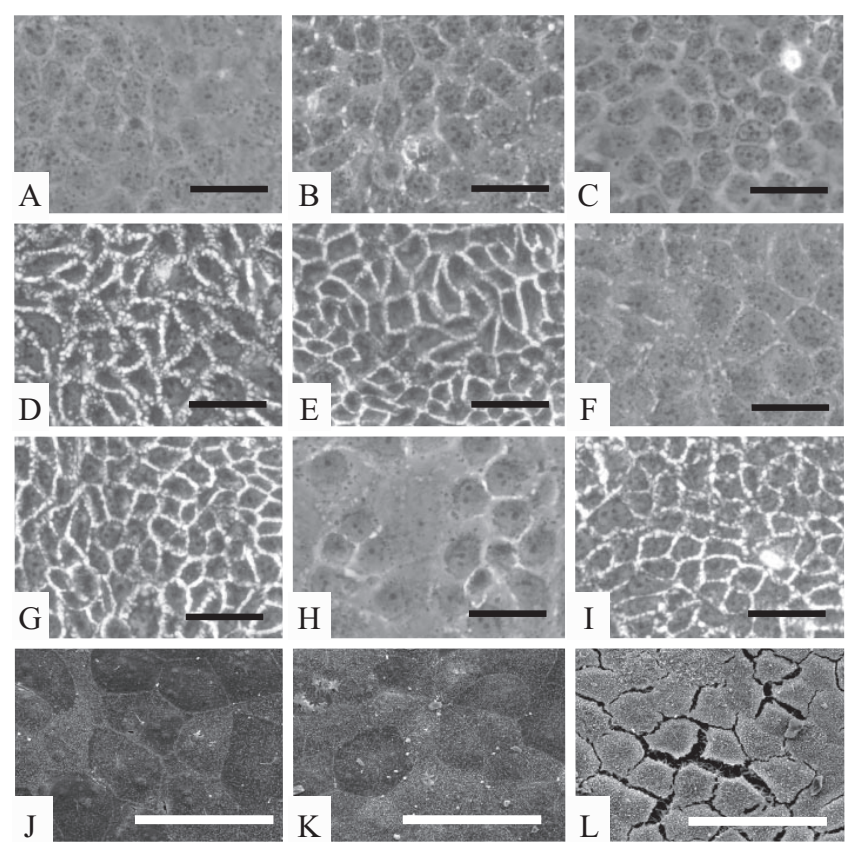

Figure 2. Morphology of subcloned HCE-T cells. Shown are subcloned HCE-T cells 2 weeks after they reached confluence (A, HCE-T-2; $\mathbf{B},-3 ; \mathbf{C},-6 ; \mathbf{D},-13 ; \mathbf{E},-15 ; \mathbf{F},-17 ; \mathbf{G},-20 ; \mathbf{H},-21$; and $\mathbf{I},-22)$. Note the marked difference in the appearance of the cell-to-cell borders. (J-L) SEM of subcloned HCE-T cells showing that HCE-T-2 (J) and - $6(\mathbf{K})$ cells were in close contact with cells and exhibited tightly apposed cell borders. On the other hand, individual HCE-T-15 cells (L) were clearly separate and their cell borders easily identifiable. Scale bar, $50 \mu \mathrm{m}$. 


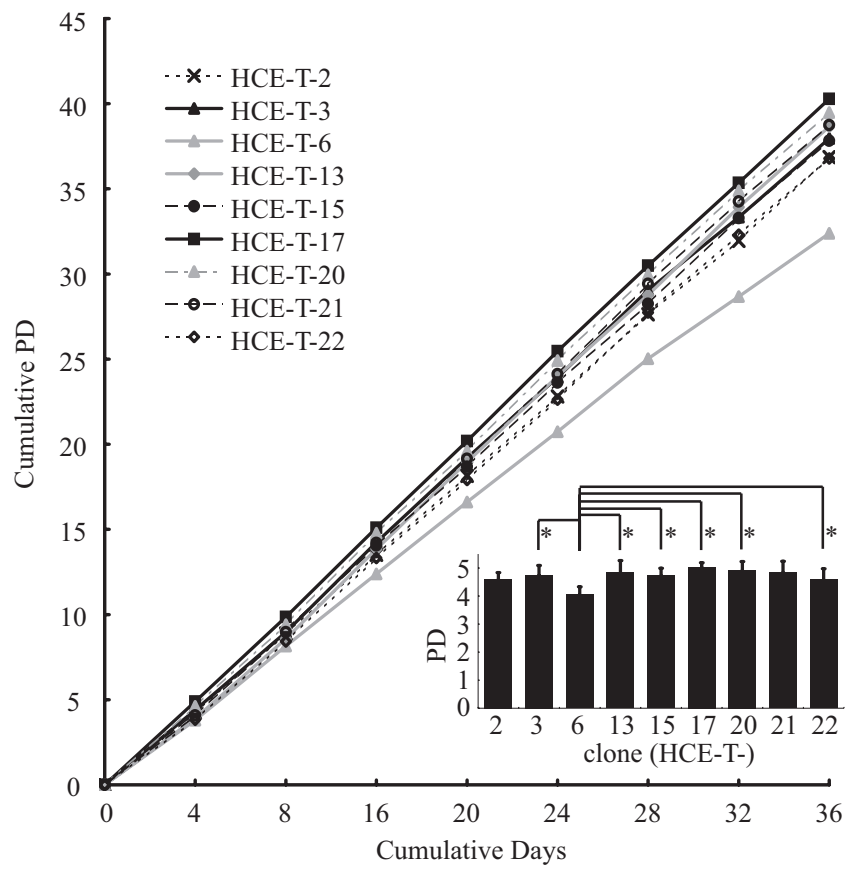

Figure 3. Cell growth kinetics in each subclone. Growth kinetics was quantitatively measured as population doubling (PD) at each passage. Cumulative PD was plotted against cumulative days. Inset: The PD values over passages were averaged for each subclone. * Statistical significance as judged by the Scheffé test at a risk rate of 5\%.

\section{Cell Morphology}

A limited-dilution method was used to obtain nine subclones (HCE-T-2, -3, -6, -13, -15, -17, -20, -21, and -22) as monoclonal, growth-competent cell populations. During their growth (confluence $<90 \%$ ), their cellular shapes were almost identical. However, after the subclones reached confluence, they acquired their proper cell shape. As shown in Figures 2A-I, subclones HCE-T-13, 15, 20, and 22 had clearly distinguishable cell-to-cell borders; cell-to-cell borders in the other subclones were far more difficult to distinguish. SEM data were consistent with this observation, as subclone HCE-T-15 exhibited easily identifiable cell borders compared with subclones HCE-T-2 and -6 whose cells appeared tightly apposed, thus obscuring individual cell borders (Figs. 2J-L).

\section{Growth Kinetics}

The growth kinetics of the subcloned HCE-T cells was subjected to PD analysis. As shown in Figure 3, there was a slight, yet significant variation in growth rate among the subclones $(P=5.2 \times 10-6$ (ANOVA, Fig. 3, inset). The maximum growth rate was found in the HCE-T-17 cells, whereas the minimum growth rate occurred in the HCE-T- 6 cells. The difference between these two subclones was approximately 7.9 PDs at 32 cumulative days, indicating that at day 32, HCE-T-17 cells exceeded HCE-T-6 cells by approximately 240 -fold $\left(\doteqdot 2^{7.9}\right)$.

\section{Transepithelial Electrical Resistance}

Because there were significant differences among the subclones in the appearance of the cell-to-cell borders, we examined the epithelial barrier function by measuring TER. As shown in Figure 4, TER varied significantly among the nine subclones, with $P<0.01$ at all measurements (ANOVA). Of note, the subclones with clearly distinguishable cell-to-cell borders (HCE-T-13, -15, -20, and -22) had an inclination toward a rapid initial increase and higher TER than did other subclones exhibiting hardly distinguishable cell-to-cell borders (HCE-T-2, $-3,-6,-17$ and -21 ).

\section{Transfection and Transcription Efficiency}

Transgene efficiency can vary greatly among different types of cells. This was also the case among the subcloned HCE-T cells in our study (Fig. 5A), and although the variance among the subclones was relatively small, it was statistically significant (ANOVA, $P=0.01$ ). However, the transcriptional activity obtained with the luciferase (Fig. 5B) or the GFP (Fig. 5C) reporter genes demonstrated a larger amount of variation among the subcloned HCE-T cells, and that variation was statistically significant (ANOVA, $P=2.9 \times 10^{-14}$ and $3.7 \times 10^{-13}$, respectively). It is noteworthy that the transcriptional activity of these

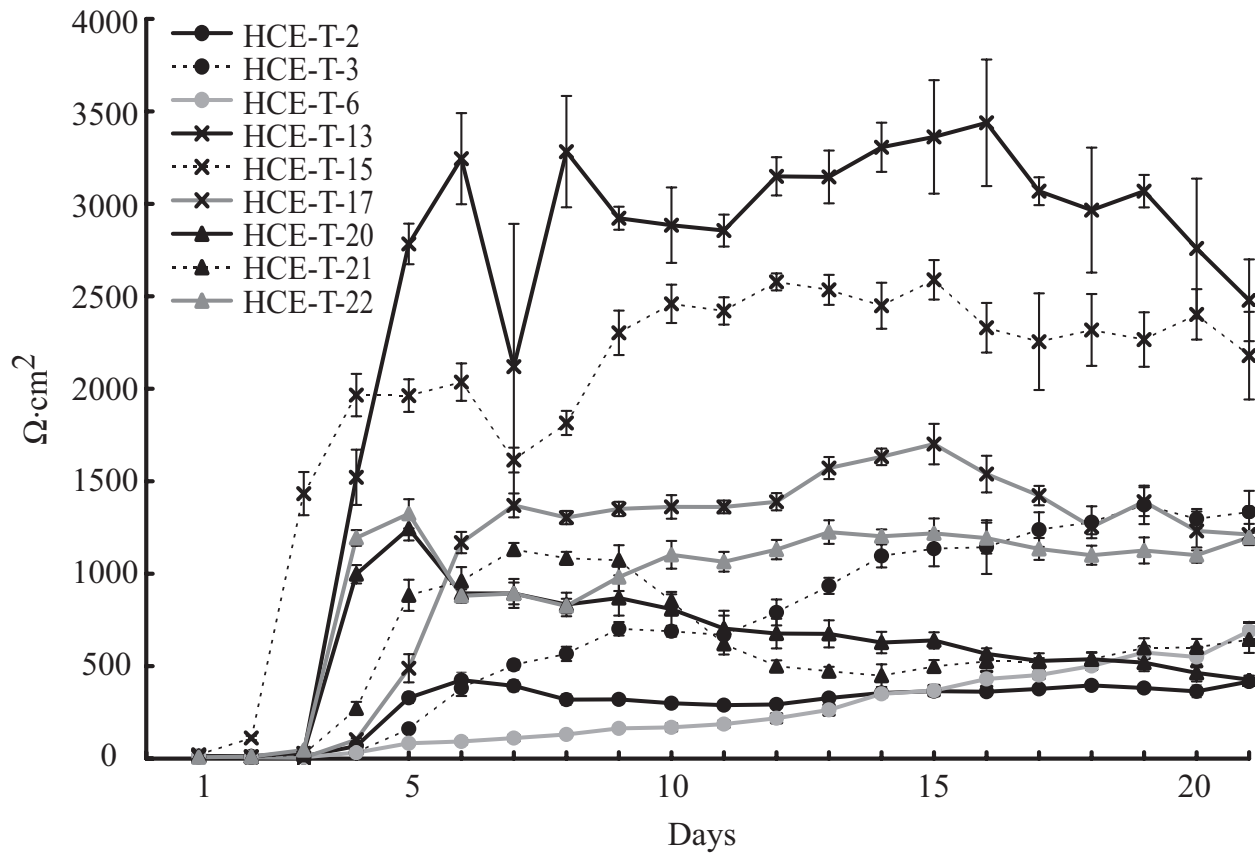

FIgURE 4. TER. Epithelial barrier function was assessed the as TER for each of the subcloned HCE-T cells. Each of the subloned cells was seeded at day 0 . The number of replicates for each subclone was 5. TER varied significantly among the nine subclones with $P<0.01$ at all measurements (ANOVA). The presence of statistical significance was evaluated by the Scheffé test as listed in Supplementary Table S1, http://www. iovs.org/cgi/content/full/50/2/604/DC1. 

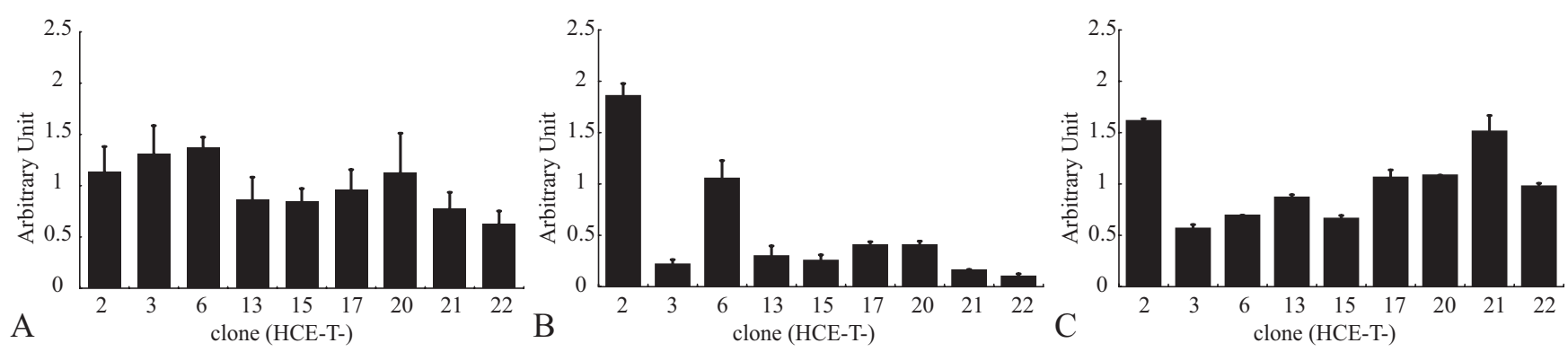

FIGURE 5. Transfection and transcription efficiency. Transfection (A) and transcriptional efficiency for luciferase (B) and GFP vector (C) were assessed for each of the HCE-T subclones. Each experiment was performed in triplicate. The variations in the data of these three experiments were statistically significant (ANOVA, $P=0.01,2.9 \times 10^{-14}$ and $3.7 \times 10^{-13}$, respectively). Although the variation in transfection efficiency was relatively small, the transcriptional efficiency of both vectors varied to a greater degree among the HCE-T subclones. Presence of statistical significance was evaluated by the Scheffé test as listed in Supplementary Table S2, http://www.iovs.org/cgi/content/full/50/2/604/DC1.

two reporter genes did not coincide with each other. Since these reporter genes are regulated under different promoters, it is probable that the composition of the transcriptional factors is different in each of the subclones and that the observed differences among the subclones may be attributable to this heterogeneity.

\section{Heterogeneity in the Locus Copy Number among the HCE-T Subclones}

Since the observed heterogeneous cellular features may be at least partially attributable to genomic heterogeneity, we quantitated the copy number of some selected genomic loci with real-time PCR against the subcloned HCE-T cells (Fig. 6). Of the six analyzed loci (three for gained and three for lost loci), five were found to be variable among the HCE-T subclones, and that variability was statistically significant (ANOVA, $1.1 \times$ $10^{-3}, 2.2 \times 10^{-7}, 4.6 \times 10^{-3}$, and $2.1 \times 10^{-5}$ for $F D X 1$, MCF2, PPML1, and PCDH1O, respectively). To validate the results of real-time PCR, CFISH was performed against a FDX1 gene locus (Fig. 7). The copy number of the FDX1 gene locus in each of the HCE-T subclones was almost identical with, but slightly smaller than that estimated by real-time PCR, possibly because in the cFISH analysis, we recognized two closely residing signals as a twin signal due to a sister chromatid formation and thus counted it as one copy, while in real-time PCR analysis, such cases should theoretically correspond to two copies.

\section{Integration of SV40-LTAG}

To confirm that all the subcloned HCE-T cells derived from a unique single cell, we performed genomic Southern blot analysis. Pst I digestion of genomic DNA from all HCE-T subclones produced a single band of approximately $1.6 \mathrm{~kb}$ (Fig. 8B), thus providing evidence that all the subclones were descended from a single cell. Inverse PCR analysis disclosed that the integration site of SV40-LTAG was 9p22.1 (Fig. 8E), between bases $18,699,829$ and 18,699,830 (base numbers assigned by the UCSC Genome Bioinformatics Group; Mar. 2006 Assembly; http://genome.ucsc.edu/index.html University of California at Santa Cruz). Of interest, this region was close to a known
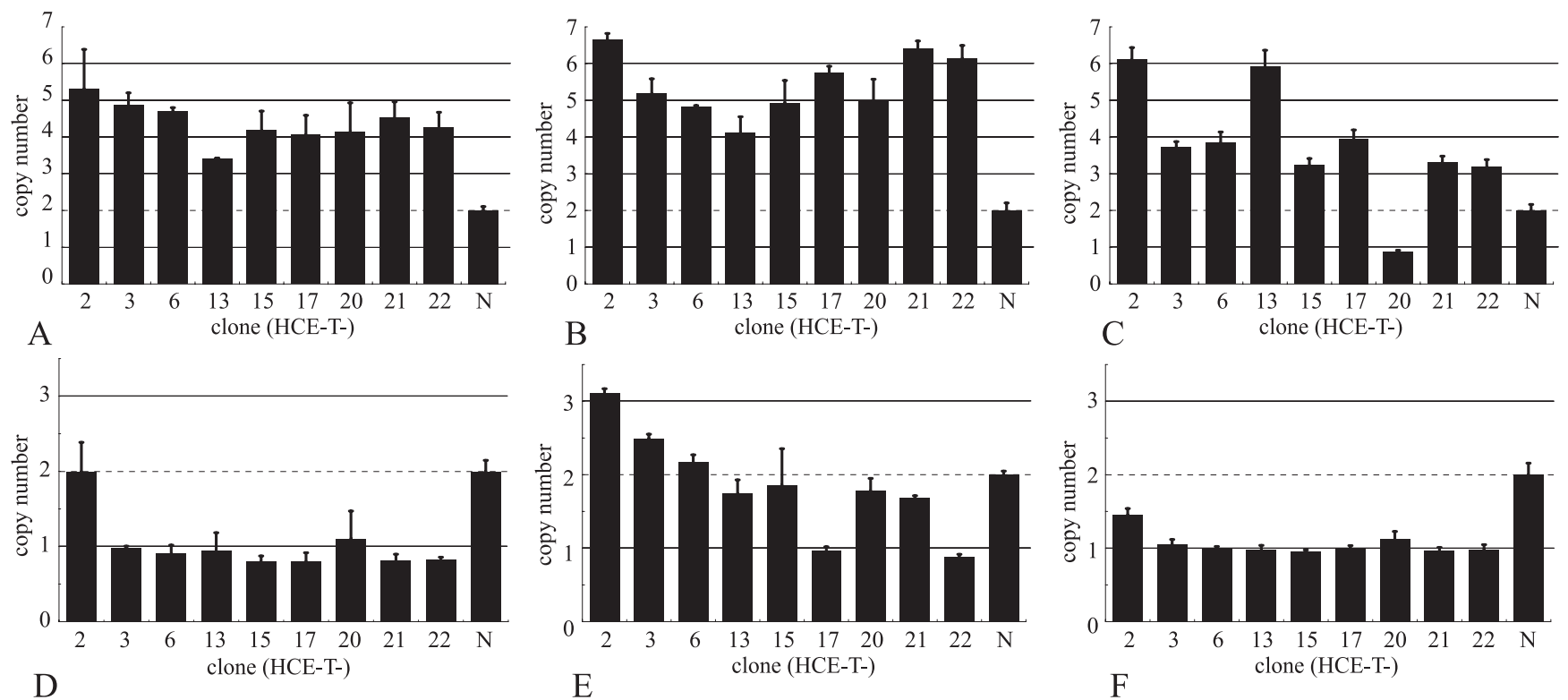

FIGURE 6. Quantitation of locus copy number by real-time PCR. Genomic aberrations in each of the subcloned HCE-T cells were quantitatively measured by real-time PCR. Primer pairs were selected from the established database of sequence-tagged sites for genomic loci with confirmed gain (A, AMOTL1, 11q14.3; B, FDX1, 11q22; C, MCF2, Xq27) or loss (D, PPM1L, 3q26.1; E, PCDH1O, 4q28.3; F, CSMD1, 8p23.2) in HCE-T cells as determined by array CGH analysis. All data were first normalized with data from an unchanged locus (CREB5, 7p15.1) and further normalized so that the copy number of the normal genome $(\mathrm{N})$ was 2 . All experiments were performed in duplicate. The presence of statistical significance was evaluated by the Scheffé test as listed in Supplementary Table S2, http://www.iovs.org/cgi/content/full/50/2/604/DC1. 

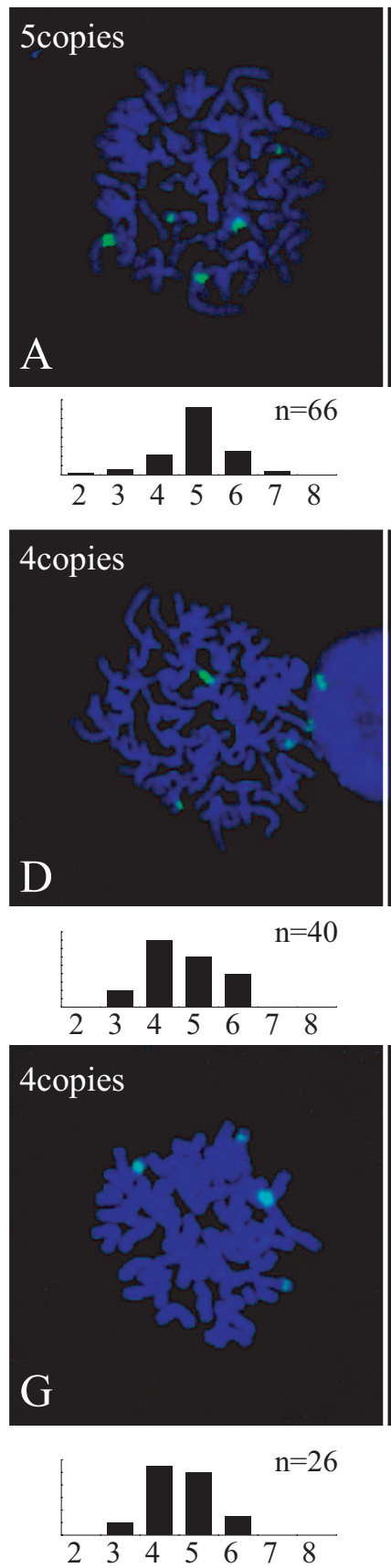
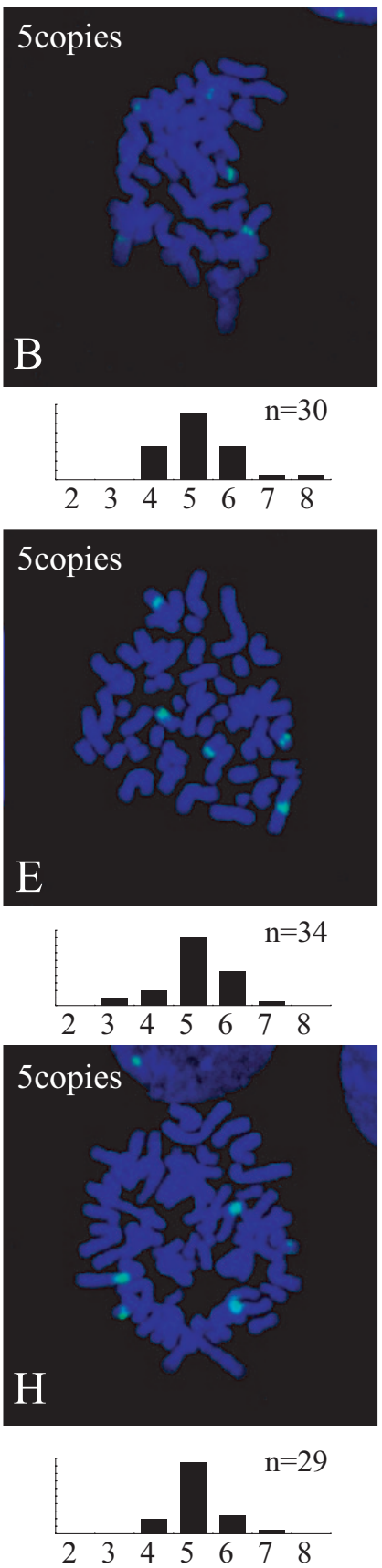

fragile site FRA9G (9p22.2), ${ }^{28}$ suggesting the possible relationship between genomic fragility and the SV40-LTAG integration as previously reported. ${ }^{29}$

\section{EST Analysis}

Next, we identified genes dominantly expressed in the HCE-T cells. We identified 740 genes as dominant transcripts in 1135 sequenced clones derived from 1728 selected colonies. As shown in Table 3, most of the dominantly transcribed genes were ribosomal protein subunits, suggesting that protein synthesis may be accelerated in this cell line. Unexpectedly, this profile is quite distinct from that of in vivo corneal epithelial cells. ${ }^{33}$ Most of the corneal epithelial-specific genes, such as keratin 12 (KRT12), ${ }^{33,34}$ KRT3, or aldehyde dehydrogenase 3 $(A L D H 3 A 1),{ }^{35}$ were not identified in the current analysis although KRT3 and ALDH enzyme activity was immunohisto-
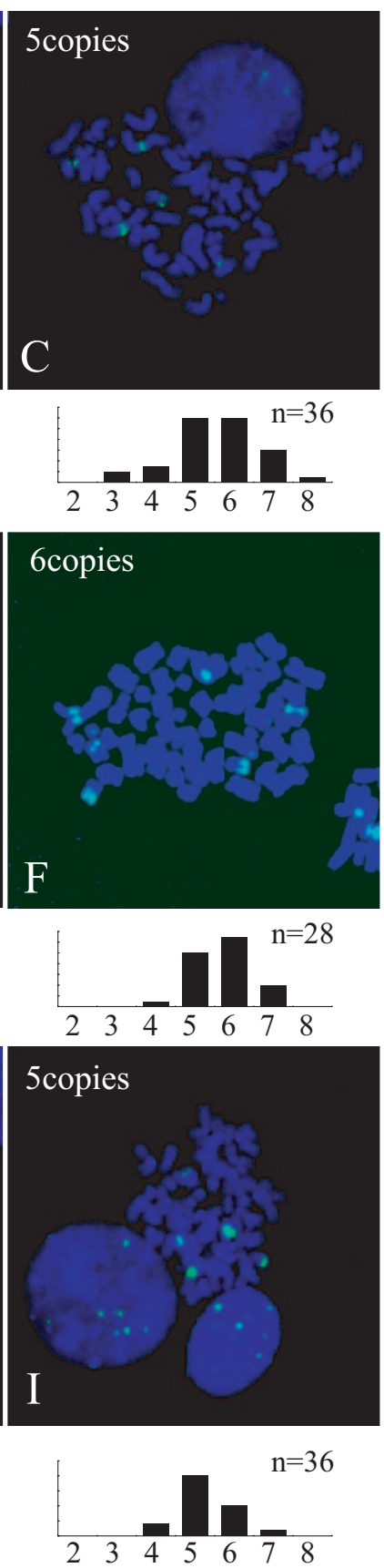

FigURE 7. Quantitation of locus copy number by cFISH. Numerical aberrations at the $F D X 1$ gene locus were assessed by cFISH against each HCE-T subclone (A, HCE-T-2; B, -3; C, $-6 ; \mathbf{D},-13 ; \mathbf{E},-15 ; \mathbf{F},-17 ; \mathbf{G},-20 ; \mathbf{H},-21$; and $\mathbf{I},-22$ ). Pictures demonstrate the results of cFISH for each of the subcloned HCE-T cells. Green denotes hybridization signal and blue denotes counterstain with DAPI. The copy number was determined as a mode value of the copy number data (bar graphs below the images) obtained from at least 20 metaphase chromosome spreads. Two closely aligned signals were judged as a twin signal due to sister chromatid formation and thus were counted as one copy in this analysis.

chemically or biochemically confirmed in the initial study. ${ }^{1} \mathrm{We}$ posit that these genes are transcriptionally repressed in the current batch of this cell line, possibly because these genes are not indispensable for the maintenance of this cell line.

\section{Discussion}

Our array CGH analysis indicated that the genomic content of HCE-T cells was altered. Our study also documented that HCE-T cells were composed of heterogeneous cell populations. Considering the nature of SV40-LTAG, our results may be attributable, at least partially, to the fact that HCE-T cells lack functional TP53 and RB1 proteins, which play critical roles in repairing or removing cells with an anomalous genome. Therefore, although HCE-T cells may initially harbor a normal healthy genome, their genomic content may have been gradually al- 


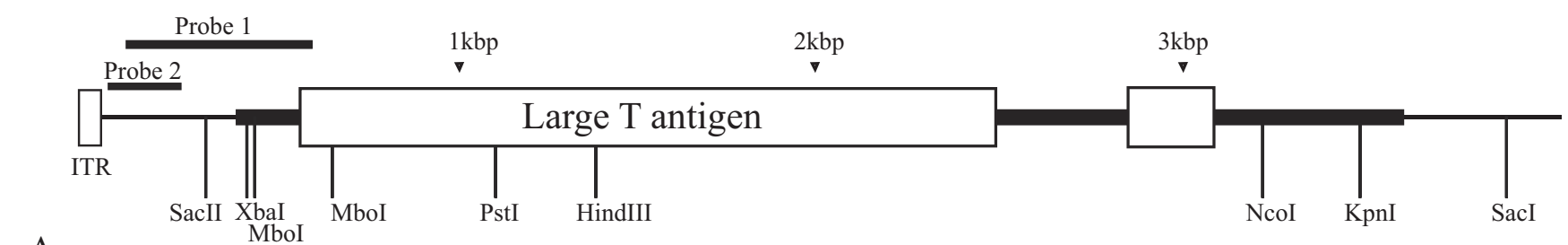

A clone (HCE-T-)
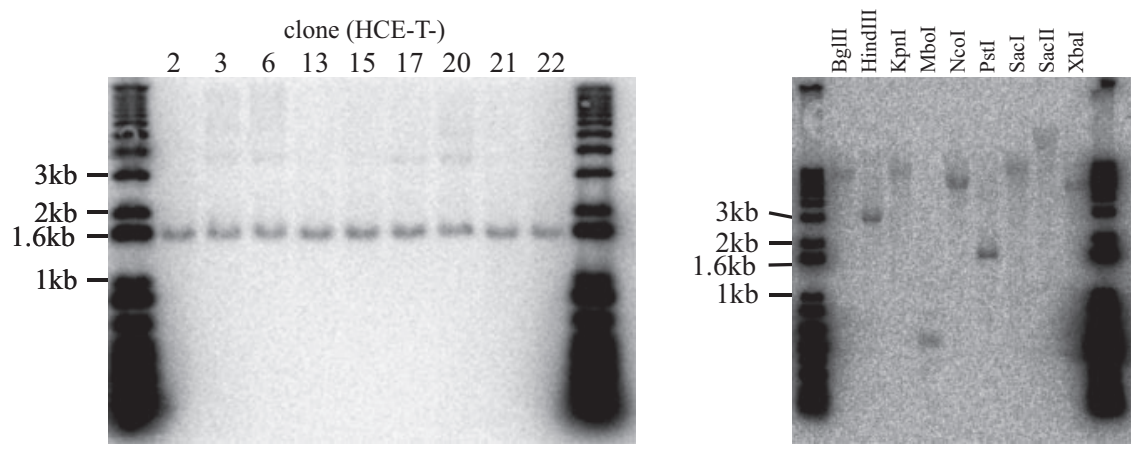

$\mathrm{B}$

C

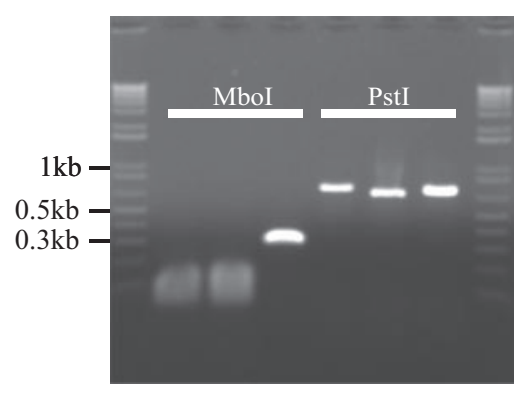

D

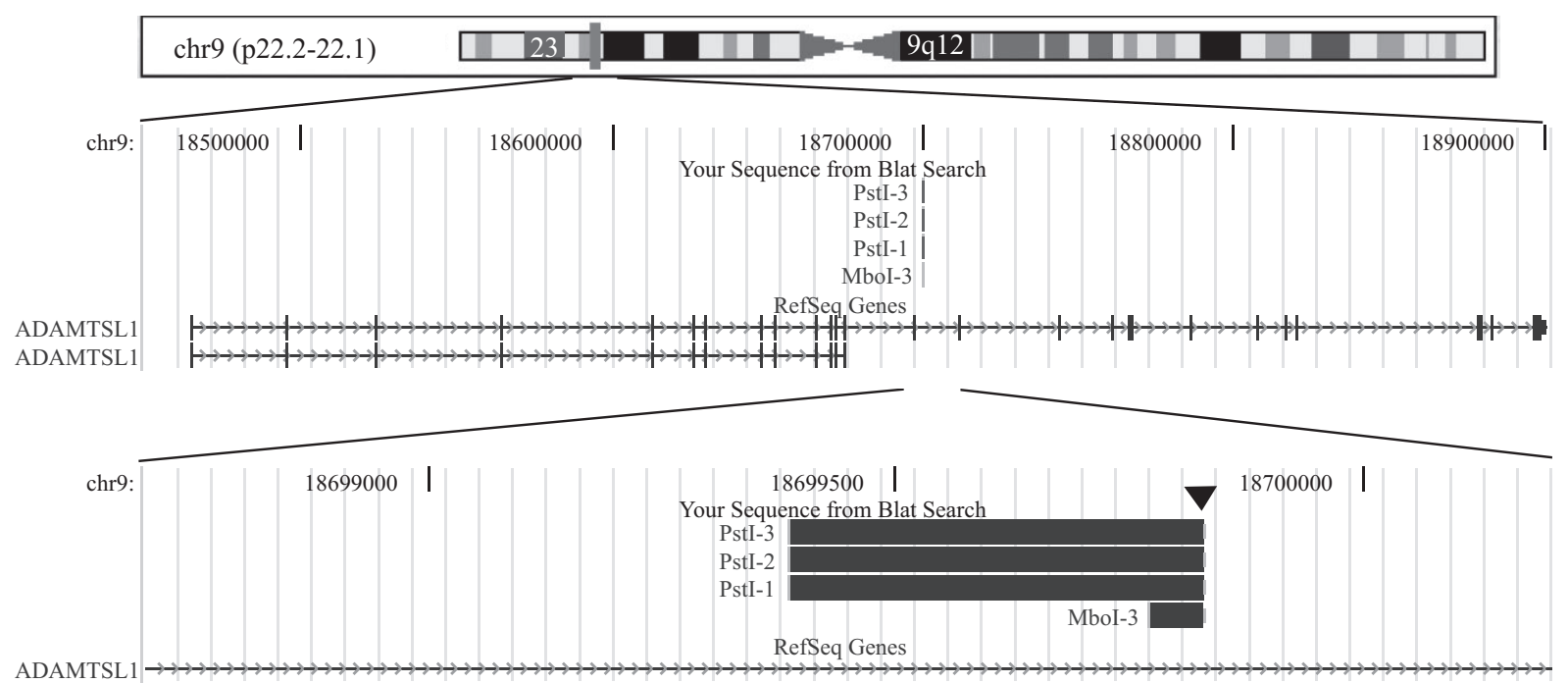

$\mathrm{E}$

Figure 8. Genomic integration of the SV40-LTAG. (A) Schematic representation of the restriction enzyme map of the left arm of the adenoviral vector harboring SV40-LTAG. Empty boxes: SV40-LTAG open reading frame; bold lines: its intronic and flanking sequences derived from the SV40 viral genome. (B) Copy numbers and genomic integration of SV40-LTAG were determined by genomic Southern blot analysis using probe 1. All subclones demonstrated an identical single band at approximately $1.6 \mathrm{~kb}$. (C) To select the optimal restriction enzyme for inverse PCR analysis, Southern blot analysis was performed with probe 2 against genomic DNA (HCE-T-15) digested with various restriction enzymes. MboI and PstI were selected because they generated relatively shorter positive bands than other enzymes. (D) Successful PCR amplification was obtained with one primer pair for MboI- and three primer pairs for PstI-digested DNA. (E) Sequence analysis of the amplified products of inverse PCR revealed the genomic integration site of SV40-LTAG at p22.1 of chromosome 9. Black triangle: integration site. The results confirmed that other subclones manifested the same genomic integration site for SV40-LTAG.

tered by each cell division and might currently still be in the process of changing.

Naturally occurring cancers have been reported to manifest genomic aberration profiles that reflect their original cell types. ${ }^{22}$ Neoplasms evolved from keratinocytes, such as esophageal $^{36,37}$ or cervical squamous cell carcinoma, ${ }^{38-40}$ are characterized by the amplification of $3 \mathrm{q}, 5 \mathrm{p}$, and $8 \mathrm{q}$. We found that of these, $3 q$ and $8 \mathrm{q}$ were also amplified in HCE-T cells, suggesting that these genomic regions are important even for SV40-LTAG-induced immortalization of keratinocyte-type cells.

The gain of oncogenes and the loss of tumor-suppressor genes represent crucial events during the stepwise process of oncogenic transformation. In this study, of particular interest was that $c-m y c$, a major proto-oncogene $e^{41,42}$ that activates transcription of the hTERT gene, ${ }^{43}$ is significantly amplified. The hTERT gene is a rate-limiting factor for telomerase, ${ }^{44-46} \mathrm{a}$ prerequisite holoenzyme for naturally occurring carcinogenesis $^{47-49}$ and artificial immortalization ${ }^{50,51}$ of eukaryotic cells in bypassing the second bottleneck for immortalization (M2 ${ }^{15}$ ). Moreover, TP53 and RB1, two major tumor-suppressor genes, deserve attention because they are inhibited by SV40-LTAG and are lost or mutated in various kinds of cancers. ${ }^{52,53}$ We found that their genomic loci, p13.1 on chromosome 17 and region 14.2 on chromosome 13, long arm, respectively, remained 
Table 3. List of the Top 20 Genes Highly Expressed in HCE-T Cells

\begin{tabular}{rcccll}
\hline Rank & $\begin{array}{c}\text { Total } \\
\text { Occurrences* }\end{array}$ & Librariest & $\begin{array}{c}\text { Occurrences in } \\
\text { HCE-T Cells }\end{array}$ & GenBank Entry & \\
\hline 1 & 384 & 54 & 15 & NM_012423.2 & Ribosomal protein L13a (RPL13A) \\
2 & 301 & 47 & 12 & NM_000990.4 & Ribosomal protein L27a (RPL27A) \\
2 & 346 & 45 & 12 & NM_001032.3 & Ribosomal protein S29 (RPS29) \\
2 & 97 & 32 & 12 & NM_001000.2 & Ribosomal protein L39 (RPL39) \\
5 & 407 & 53 & 10 & NM_001035267.1 & Ribosomal protein L41 (RPL41) \\
5 & 216 & 47 & 10 & NM_000989.2 & Ribosomal protein L30 (RPL30) \\
5 & 10 & 1 & 10 & NM_002281.2 & Keratin 81 (KRT81) \\
8 & 629 & 62 & 9 & NM_001402.5 & Eukaryotic translation elongation factor 1 alpha 1 (EEF1A1) \\
8 & 123 & 33 & 9 & NM_000978.3 & Ribosomal protein L23 (RPL23) \\
8 & 315 & 54 & 9 & NM_021109.2 & Thymosin, beta 4, X-linked (TMSB4X) \\
8 & 231 & 43 & 8 & NM_002032.2 & Ferritin, heavy polypeptide I (FTH1) \\
12 & 460 & 57 & 7 & NM_001012.1 & Ribosomal protein S8 (RPS8) \\
12 & 218 & 45 & NM_001021.3 & Ribosomal protein S17 (RPS17) \\
14 & 267 & 49 & 7 & NM_002948.2 & Similar to ribosomal protein S18 (LOC730754) \\
14 & 84 & 29 & Ribosomal protein L15 (RPL15) \\
14 & 225 & 44 & 6 & NM_000987.3 & Ribosomal protein L26 (RPL26) \\
17 & 197 & 45 & 601101.2 & Actin, beta (ACTB) \\
17 & 176 & 46 & NM_001019.4 & Ribosomal protein S15a (RPS15A) \\
17 & 197 & 53 & NM_001035258.1 & Ribosomal protein L38 (RPL38) \\
17 & 45 & 23 & NR_003606.1 & Chromosome 20 open reading frame 199 (C20)rf199) \\
\hline
\end{tabular}

Listed are the top 20 genes highly expressed in HCE-T cells. Of these, 13 are ribosomal protein subunits. Keratin 81, whose expression has been reported in differentiating hair cortical cells during anagen, ${ }^{30}$ was dominantly and specifically expressed in this cell line. All sequence data have been deposited in the NCB1 dbEST database (http://www.ncbi.nlm.nih.gov/dbEST/, National Center for Biotechnology Information, Bethesda, MD) and are freely accessible under accession numbers BY998675 through BY999809.

* Occurrences of the gene in the 63 libraries investigated in the BodyMap project. ${ }^{31,32}$

$\dagger$ Number of the libraries in which the gene occurred at least one time.

unchanged in this cell line. Our results appear to be reasonable, given that the SV40-LTAG suppresses functions of these genes only at the protein level, not at the genomic level.

Besides aberrant genomic content, our current data reveal that the gene expression profiles of the HCE-T cells were markedly different from those of in vivo corneal epithelial cells. Although it can be explained by several theoretical factors, a previous report ${ }^{54}$ indicated that altered gene expression may be attributable to altered genomic content. Therefore, most of the genes whose copy numbers were confirmed to be increased or decreased in our study may be differentially expressed between in vivo corneal epithelial cells and HCE-T cells. Also, besides such a gene dosage aspect, epigenetic alteration may play a large influence on altered gene expression and cellular features. For example, our preliminary data indicated that the KRT12 gene, whose genomic locus (17q21.2) was unchanged in the present study, is highly expressed in corneal epithelial cells in vivo, ${ }^{34}$ but is virtually absent in the HCE-T cells, possibly due to its genomic methylation status (Kawasaki S, et al. IOVS 2007; 48:ARVO E-Abstract 2724). Taken together, HCE-T cells appear to be considerably different from in vivo corneal epithelial cells, possibly due to various gene regulation mechanisms.

In summary, our current data demonstrate that the genomic content of HCE-T cells is altered and that the cells are heterogeneous. Based on findings reported herein, we suggest that investigators who are planning to use this cell line must first consider whether it is appropriate for their study purposes. Furthermore, our observations should alert researchers to the fact that any results obtained from this cell line need to be carefully interpreted. Last, it is probable that the HCE-T cells maintained or deposited at various laboratories or cell banks are not genetically identical, especially when they are subcultured too many times. Therefore, and as is often said, researchers should use this cell line with a passage number as small as possible. It is our hope that the findings in this report helps contribute to the success of future studies employing the HCE-T cell line.

\section{Acknowledgments}

The authors thank John Bush for reviewing the manuscript, Takeshi Sugimoto for excellent technical advice in analyzing the array CGH data, and Tatsuo Terashima for excellent technical advice on the statistical analysis.

\section{References}

1. Araki-Sasaki K, Ohashi Y, Sasabe T, et al. An SV40-immortalized human corneal epithelial cell line and its characterization. Invest Ophthalmol Vis Sci. 1995;36:614-621.

2. Kahn CR, Young E, Lee IH, Rhim JS. Human corneal epithelial primary cultures and cell lines with extended life span: in vitro model for ocular studies. Invest Ophthalmol Vis Sci. 1993;34: 3429-3441.

3. Offord EA, Sharif NA, Mace K, et al. Immortalized human corneal epithelial cells for ocular toxicity and inflammation studies. Invest Opbthalmol Vis Sci. 1999;40:1091-1101.

4. Griffith M, Osborne R, Munger R, et al. Functional human corneal equivalents constructed from cell lines. Science. 1999;286:21692172.

5. Rheinwald JG, Hahn WC, Ramsey MR, et al. A two-stage, p16(INK4A)- and p53-dependent keratinocyte senescence mechanism that limits replicative potential independent of telomere status. Mol Cell Biol. 2002;22:5157-5172.

6. Mohan RR, Possin DE, Sinha S, Wilson SE. Development of genetically engineered tet HPV16-E6/E7 transduced human corneal epithelial clones having tight regulation of proliferation and normal differentiation. Exp Eye Res. 2003;77:395-407.

7. Robertson DM, Li L, Fisher S, et al. Characterization of growth and differentiation in a telomerase-immortalized human corneal epithelial cell line. Invest Ophthalmol Vis Sci. 2005;46:470-478.

8. Saarinen-Savolainen $\mathrm{P}$, Jarvinen $\mathrm{T}$, Araki-Sasaki $\mathrm{K}$, Watanabe $\mathrm{H}$, Urtti A. Evaluation of cytotoxicity of various ophthalmic drugs, eye drop excipients and cyclodextrins in an immortalized human corneal epithelial cell line. Pharm Res. 1998;15:1275-1280.

9. Papa V, Leonardi A, Getuli C, et al. Effect of ofloxacin and netilmicin on human corneal and conjunctival cells in vitro. $J$ Ocul Pharmacol Ther. 2003;19:535-545. 
10. Kimura K, Teranishi S, Yamauchi J, Nishida T. Role of JNK-dependent serine phosphorylation of paxillin in migration of corneal epithelial cells during wound closure. Invest Ophthalmol Vis Sci. 2008;49:125-132.

11. Yin J, Xu K, Zhang J, Kumar A, Yu FS. Wound-induced ATP release and EGF receptor activation in epithelial cells. J Cell Sci. 2007;120: 815-825.

12. Van Doren K, Gluzman Y. Efficient transformation of human fibroblasts by adenovirus-simian virus 40 recombinants. Mol Cell Biol. 1984; 4:1653-1656.

13. Lane DP, Simanis V, Bartsch R, et al. Cellular targets for SV40 large T-antigen. Proc R Soc Lond B Biol Sci. 1985;226:25- 42.

14. Cobrinik D. Pocket proteins and cell cycle control. Oncogene. 2005;24:2796-2809.

15. Shay JW, Wright WE, Werbin H. Defining the molecular mechanisms of human cell immortalization. Biochim Biophys Acta. $1991 ; 1072: 1-7$

16. Goodrich DW. The retinoblastoma tumor-suppressor gene, the exception that proves the rule. Oncogene. 2006;25:5233-5243.

17. Callegari AJ, Kelly TJ. Shedding light on the DNA damage checkpoint. Cell Cycle. 2007;6:660-666.

18. Harrington EA, Bruce JL, Harlow E, Dyson N. pRB plays an essential role in cell cycle arrest induced by DNA damage. Proc Natl Acad Sci U S A 1998;95:11945-11950.

19. Rodier F, Campisi J, Bhaumik D. Two faces of p53: aging and tumor suppression. Nucleic Acids Res. 2007;35:7475-7484.

20. Hollstein M, Moeckel G, Hergenhahn M, et al. On the origins of tumor mutations in cancer genes: insights from the p53 gene. Mutat Res. 1998;405:145-154.

21. Tchinda J, Volpert S, McNeil N, et al. Multicolor karyotyping in acute myeloid leukemia. Leuk Lymphoma. 2003;44:1843-1853.

22. Myllykangas S, Himberg J, Bohling $\mathrm{T}$, et al. DNA copy number amplification profiling of human neoplasms. Oncogene. 2006;25: $7324-7332$.

23. Stewart N, Bacchetti S. Expression of SV40 large T antigen, but not small $t$ antigen, is required for the induction of chromosomal aberrations in transformed human cells. Virology. 1991;180: 49-57.

24. Ray FA, Peabody DS, Cooper JL, Cram LS, Kraemer PM. SV40 T antigen alone drives karyotype instability that precedes neoplastic transformation of human diploid fibroblasts. J Cell Biochem. 1990; 42:13-31.

25. Ebato B, Friend J, Thoft RA. Comparison of central and peripheral human corneal epithelium in tissue culture. Invest Ophthalmol Vis Sci. 1987;28:1450-1456.

26. Okubo K, Hori N, Matoba R, et al. Large scale cDNA sequencing for analysis of quantitative and qualitative aspects of gene expression. Nat Genet. 1992;2:173-179.

27. Futreal PA, Coin L, Marshall M, et al. A census of human cancer genes. Nat Rev Cancer. 2004;4:177-183.

28. Sawinska M, Schmitt JG, Sagulenko E, et al. Novel aphidicolininducible common fragile site FRA9G maps to 9p22.2, within the C9orf39 gene. Genes Chromosomes Cancer. 2007;46:991-999.

29. Mishmar D, Rahat A, Scherer SW, et al. Molecular characterization of a common fragile site (FRA $7 \mathrm{H}$ ) on human chromosome 7 by the cloning of a simian virus 40 integration site. Proc Natl Acad Sci U S A 1998;95:8141-8146.

30. Bowden PE, Hainey SD, Parker G, et al. Characterization and chromosomal localization of human hair-specific keratin genes and comparative expression during the hair growth cycle. $J$ Invest Dermatol. 1998;110:158-164.

31. Kawamoto S, Yoshii J, Mizuno K, et al. BodyMap: a collection of 3' ESTs for analysis of human gene expression information. Genome Res. 2000;10:1817-1827.
32. Hishiki T, Kawamoto S, Morishita S, Okubo K. BodyMap: a human and mouse gene expression database. Nucleic Acids Res. 2000;28: $136-138$

33. Nishida K, Adachi W, Shimizu-Matsumoto A, et al. A gene expression profile of human corneal epithelium and the isolation of human keratin 12 cDNA. Invest Ophthalmol Vis Sci. 1996;37: $1800-1809$

34. Kurpakus MA, Stock EL, Jones JC. Expression of the $55-\mathrm{kD} / 64-\mathrm{kD}$ corneal keratins in ocular surface epithelium. Invest Ophthalmol Vis Sci. 1990;31:448-456.

35. Abedinia M, Pain T, Algar EM, Holmes RS. Bovine corneal aldehyde dehydrogenase: the major soluble corneal protein with a possible dual protective role for the eye. Exp Eye Res. 1990;51:419-426.

36. Su M, Chin SF, Li XY, et al. Comparative genomic hybridization of esophageal adenocarcinoma and squamous cell carcinoma cell lines. Dis Esophagus. 2006;19:10-14.

37. Wang LD, Qin YR, Fan ZM, et al. Comparative genomic hybridization: comparison between esophageal squamous cell carcinoma and gastric cardia adenocarcinoma from a high-incidence area for both cancers in Henan, northern China. Dis Esophagus. 2006;19:459-467.

38. Rao PH, Arias-Pulido H, Lu XY, et al. Chromosomal amplifications, $3 \mathrm{q}$ gain and deletions of $2 \mathrm{q} 33-\mathrm{q} 37$ are the frequent genetic changes in cervical carcinoma. BMC Cancer. 2004;4:5.

39. Huang FY, Kwok YK, Lau ET, et al. Genetic abnormalities and HPV status in cervical and vulvar squamous cell carcinomas. Cancer Genet Cytogenet. 2005;157:42-48.

40. Choi YW, Bae SM, Kim YW, et al. Gene expression profiles in squamous cell cervical carcinoma using array-based comparative genomic hybridization analysis. Int J Gynecol Cancer. 2007;17: 687-696.

41. Nesbit CE, Tersak JM, Prochownik EV. MYC oncogenes and human neoplastic disease. Oncogene. 1999;18:3004-3016.

42. Schmidt EV. The role of c-myc in cellular growth control. Oncogene. 1999;18:2988-2996.

43. Wu KJ, Grandori C, Amacker M, et al. Direct activation of TERT transcription by c-MYC. Nat Genet. 1999;21:220-224.

44. Ito $\mathrm{H}$, Kyo $\mathrm{S}$, Kanaya $\mathrm{T}$, et al. Expression of human telomerase subunits and correlation with telomerase activity in urothelial cancer. Clin Cancer Res. 1998;4:1603-1608.

45. Kanaya T, Kyo S, Takakura M, et al. hTERT is a critical determinant of telomerase activity in renal-cell carcinoma. Int J Cancer. 1998; 78:539-543.

46. Takakura M, Kyo S, Kanaya T, Tanaka M, Inoue M. Expression of human telomerase subunits and correlation with telomerase activity in cervical cancer. Cancer Res. 1998;58:1558-1561.

47. Counter CM, Hirte HW, Bacchetti S, Harley CB. Telomerase activity in human ovarian carcinoma. Proc Natl Acad Sci U S A. 1994;91: $2900-2904$

48. Kim NW, Piatyszek MA, Prowse KR, et al. Specific association of human telomerase activity with immortal cells and cancer. Science. 1994;266:2011-2015.

49. Shay JW, Bacchetti S. A survey of telomerase activity in human cancer. Eur J Cancer. 1997;33:787-791.

50. Nakayama J, Tahara $\mathrm{H}$, Tahara $\mathrm{E}$, et al. Telomerase activation by hTRT in human normal fibroblasts and hepatocellular carcinomas. Nat Genet. 1998;18:65-68.

51. Bodnar AG, Ouellette M, Frolkis M, et al. Extension of life-span by introduction of telomerase into normal human cells. Science. 1998; 279:349-352.

52. Nigro JM, Baker SJ, Preisinger AC, et al. Mutations in the p53 gene occur in diverse human tumour types. Nature. 1989;342:705-708.

53. Soussi T. p53 Antibodies in the sera of patients with various types of cancer: a review. Cancer Res. 2000;60:1777-1788.

54. Sugimoto T, Arai M, Shimada H, Hata A, Seki N. Integrated analysis of expression and genome alteration reveals putative amplified target genes in esophageal cancer. Oncol Rep. 2007;18:465-472. 